\title{
Uma leitura de gênero: representações de normalidade na revista Vamos Ler!, 1936-1948
}

\author{
A reading of gender: representations of normality \\ in the magazine Vamos Ler!, 1936-1948
}

\section{Carolina da Costa de Carvalho}

Mestranda, Pós-graduação em História das Ciências e da Saúde/ Casa de Oswaldo Cruz/Fiocruz. Av. Brasil, 4036, $4^{\circ}$ andar 21045-900 - Rio de Janeiro - RJ - Brasil

carolinaccarvalho@outlook.com
CARVALHO, Carolina da Costa de. Uma leitura de gênero: representações de normalidade na revista Vamos Ler!, 1936-1948. História, Ciências, Saúde - Manguinhos, Rio de Janeiro, v.24, n.3, jul.-set. 2017, p.827-834.

\section{Resumo}

A nota de pesquisa é fruto de uma investigação a respeito da circulação da normalidade, como categoria da medicina mental, entre a população leiga. A partir da hipótese de que a apropriação discursiva de categorias médicas é marcada por uma polifonia de sentidos, e não por homogeneidade, foi analisada a revista de variedades Vamos Ler! (1936-1948), caracterizada pela participação ativa do público leitor em seções de correspondência. A subjetividade contida nas cartas publicadas na revista permitiu observar que o discurso médico não era hegemônico na definição leiga de normalidade, ressaltando a presença de outros discursos - incluindo as experiências individuais dos próprios leitores - que assumiam a condição de verdade na construção das representações de homem e mulher normais.

Palavras-chave: medicina mental; normalidade; subjetividade; gênero; imprensa.

\begin{abstract}
This research note is the result of an investigation into the circulation of normality as a category of mental health among the lay population. Based on the hypothesis that the appropriation of discourse from medical categories is marked by a polyphony of meanings and not by homogeneity, this project analyzed the variety magazine Vamos Ler! (1936-1948), which featured active participation by its readers in correspondence sections. The subjectivity contained in the letters published in the magazine reveals that the medical discourse was not hegemonic in the lay definition of normality, emphasizing the presence of other discourses (including the experiences of individual readers) which assumed the condition of truth in constructing representations of normal men and women.
\end{abstract}

Keywords: mental health; normality; subjectivity; gender; press. 
$\mathrm{O}$ s anos 1930 e 1940 foram marcados por uma centralização das políticas públicas de educação e saúde enquanto parte de um projeto político modernizador que visava construir uma nação saudável e civilizada no Brasil (Fonseca, 2007). No campo da medicina, tal preocupação se expressou em propostas profiláticas que buscavam estabelecer normas para os indivíduos e regular as relações sociais, a fim de evitar o adoecimento da população e afirmar a "normalidade" como garantia da ordem social e da saúde física e mental brasileira (Venancio, 2003; Facchinetti, 2015).

Tal período também foi prolífico na discussão das relações de gênero. O voto e a ampliação do trabalho externo para as classes médias no contexto das guerras mundiais trouxeram à tona discussões sobre emancipação feminina que reverberavam para além da Europa. Na contramão dessas mudanças, as mulheres constituíam um dos alvos principais de discursos médicos que reforçavam a maternidade e a educação dos filhos enquanto responsabilidade biológica e moral feminina. Embora tais concepções tivessem grande aceitação na comunidade médica, sua transposição para a população leiga não ocorreu de forma homogênea nem passiva (Freire, 2009; Cupello, 2013).

\section{Gênero em revista}

A análise de gênero em revistas se articulou a reflexões mais aprofundadas sobre circulação e apropriação das categorias médico-mentais de "normalidade", "anormalidade" e "patologia" na construção de identidades de gênero. As considerações de Chartier (2002) a respeito das práticas e representações que caracterizam a apropriação discursiva viabilizaram problematizar a normalização social enquanto processo homogêneo, uma vez que os leigos foram compreendidos como produtores de versões de si heterogêneas. Versões influenciadas por outros discursos e pelas experiências individuais que se afirmavam enquanto referências legítimas na construção de suas identidades e visões de mundo, que puderam ser acessadas por meio da imprensa.

As revistas, além de informar sobre as novidades que conferiam ritmo moderno às cidades, expressado em bondes, rádios e cinemas, atuavam como veículos difusores de valores e hábitos, incluindo intervenções profiláticas (Luca, 2005, p.120). Ainda que cumprissem um papel normalizador enquanto formadoras de opinião (Buitoni, 2009), também contribuíram para pensar os conflitos em torno de diferentes visões de mundo, permitindo identificar em suas páginas práticas consideradas "modernas" que escapavam às normas de gênero.

Ao abordar a questão de gênero sob essa perspectiva, compreendeu-se que a diferença sexual é legitimada por discursos que a inscrevem em práticas e fatos cotidianos (Scott, 1994). Tornou-se importante, portanto, identificar os dispositivos que representavam como "natural" a divisão social e histórica que define o que é ser homem e ser mulher e os limites dessas normas, uma vez que sua apropriação também se apresentava como estratégia de negociação (Chartier, 1995).

Tais reflexões serviram de hipótese para a pesquisa ora apresentada e para a pesquisa mais ampla junto à qual foi desenvolvida: a de uma "medicalização" social relativa, caracterizada por negociações dos personagens alvo dos discursos médicos (Facchinetti, 2014). ${ }^{1}$ Buscou-se aqui analisar as representações de "normalidade" para gênero, verificando a presença ou não 
dessa categoria médica no discurso dos leitores encontrado nas correspondências trocadas com a revista de variedades Vamos Ler!, que se destacou pela significativa colaboração do público leitor em seções de aconselhamento médico e/ou sentimental.

O interesse pela troca epistolar se justificou uma vez que as cartas se apresentam como um modo de construção de si e de compartilhamento de experiências com um "outro" interlocutor (Bastos, Cunha, Mignot, 2002). As autorreflexões de leitores/as compartilhadas por "narrativas de si" permitiram acessar a dimensão mais íntima do processo de construção de identidade: a subjetividade, que possibilitou verificar que a "normalidade" se apresentava de forma diversificada para leigos. Homens e mulheres, longe de representar um papel inerte frente aos saberes em circulação, participavam ativamente da construção de suas identidades de gênero e, nessa discussão, bebiam das mais diversas fontes ao versar sobre o "normal" para ambos.

\section{Alguns percursos metodológicos}

O inicial interesse pelas cartas publicadas em Vamos Ler! se ampliou para todo o periódico, uma vez que os temas de apelo popular e a colaboração constante do público permitiram considerá-la uma representante de sua época e pensar a circulação de diferentes saberes na construção das identidades de gênero (Facchinetti, 2014). Assim, a revista passou de fonte a objeto da pesquisa, e o recorte temporal foi deslocado da Era Vargas (1930-1945), período marcado por iniciativas estatais em educação e saúde ligadas a um projeto nacionalista com o qual Vamos Ler! dialogou, para todo o período de sua publicação (1936-1948), a fim de também compreender suas redes de sociabilidade e transformações editoriais.

Por meio do software linguístico WordSmith Tools (2015), foram quantificados os assuntos mais frequentes na revista, de modo a agrupá-los em categorias segundo o vocabulário dos próprios atores (Tabela 1). Foram selecionados 1.235 textos de seções com participação dos leitores, como "Os homens são assim...", "Dê sua opinião... por 20\$000", "Retratos antropológicos", e demais matérias sobre papéis sociais e modernidade.

Tabela 1: Temas agrupados por categorias e frequência

\begin{tabular}{llr}
\hline Temas & Categorias & $\%$ \\
\hline Gênero & homem, mulher, inferioridade, superioridade, direitos & 24,6 \\
\hline Família & família, criança, maternidade, mãe, filhos, pais, casamento/matrimônio & 17,8 \\
\hline Modernidade & $\begin{array}{l}\text { tempo, trabalho, indivíduo, moderna, moderno, moda, sociedade, } \\
\text { progresso, civilização, independência, feminismo, emancipação }\end{array}$ & 11,5 \\
\hline Filosofia/Religião & vida, espírito, beleza, religião & 11,4 \\
\hline Sentimentos & $\begin{array}{l}\text { amor, sentimento, felicidade, intimidade, medo, egoísmo, orgulho, } \\
\text { altruísmo, alegria, indiferença }\end{array}$ & 11 \\
\hline Educação & educação, pedagogia, literatura, leitura & 7,4 \\
\hline Psicologia & inteligência, sensualismo/sensualidade, inconsciente, personalidade & 7 \\
\hline Nodicina mental e Saúde & higiene, eugenia, saberes psi, saúde & 6,7 \\
\hline Total & normal, anormal, loucura, doença & 2,6 \\
\hline
\end{tabular}


Isso demonstrou que "gênero" era o assunto mais abordado, sobretudo nas cartas, tanto os modelos de "homem" e "mulher" quanto o caráter de seus papéis sociais que sofriam interferência de questões típicas da "modernidade", como "trabalho", "emancipação" e "feminismo". A "família" era enfatizada como instituição onde tais funções eram reforçadas, desde o "casamento" até o bom exercício das funções de "mãe" e "pai" no cuidado com os "filhos". As cartas permitiram incorporar ainda assuntos íntimos que motivavam a busca de aconselhamento, como os "sentimentos". Dentre as referências discursivas, a "filosofia/ religião" ainda predominava nos assuntos que tratavam do "Eu", embora os saberes científicos ganhassem espaço: a "psicologia" se destacou mais do que a "medicina mental e saúde" na definição do indivíduo normal.

\section{Um "tratado de psicologia dos leitores"}

Publicada entre 1936 e 1948 por A Noite S.A. no Rio de Janeiro, Vamos Ler! apresentava-se como um "convite permanente à leitura", preocupada em fornecer uma diversidade de temas a fim de entreter seu público e, especialmente, contribuir para "a educação da Juventude Brasileira" (Mello, 15 ago. 1940, p.25).

Embora tal período seja marcado pela censura do Estado Novo (1937-1945) aos meios de comunicação, o engajamento da revista com a leitura revela uma aproximação das políticas propagandísticas do governo - sobretudo após ser incorporada ao Patrimônio da União como parte do acervo de $A$ Noite (Brasil, 1940) - e às iniciativas do Ministério da Educação e Saúde Pública durante a Reforma Capanema, que visava à reformulação do ensino e à formação de uma cultura sólida ligada à educação e ao patriotismo (Schwartzman, Bomeny, Costa, 2000). ${ }^{2}$

Além de literatura brasileira e estrangeira, publicava sobre política nacional e internacional, moda, cinema, assistência médica, psicologia, psicanálise, antropologia física, quiromancia, matemática, passatempo, discussões pedagógicas e educacionais, e também premiava leitores em concursos culturais, como fantasias carnavalescas e contos. Entre os colaboradores assíduos estavam o psicanalista Gastão Pereira da Silva, famoso na divulgação de psicanálise para leigos, a cronista Maria Luiza de Barreto Leite, o médico clínico Nicolau Ciancio e letrados como Murilo Mendes, Clóvis Ramalhete e Jorge Amado em crônicas e resenhas literárias.

O incentivo à participação do público foi tão bem aceito, que a revista era considerada pelo próprio um "tratado de psicologia dos leitores" que se sentiam "perfeitamente à vontade em suas páginas" (Miranda, 3 abr. 1941, p.44). Colaboravam em seções que publicavam cartas ou apenas respondiam formulários enviados. As mais populares eram "Dê sua opinião... por 20\$000", que premiava as melhores missivas sobre assuntos contemporâneos, e "Os homens são assim...", em que Maria Luiza mobilizava as leitoras a compartilhar o que pensavam dos homens.

Destacavam-se nas cartas as transformações pelas quais o país passava, incluídas as verificadas nos papéis sociais femininos e masculinos. As impressões sobre as novas formas de ser e agir revelam as incertezas causadas pela ruptura com a tradição, o que explica em parte a busca de aconselhamento. Assim, também importou ouvir o que os colaboradores tinham a dizer sobre tais questões. Eram médicos, jornalistas e cronistas que, reconhecidos como 
autoridade, ditavam "verdades" sobre o que era adequado/saudável para ambos os sexos - ainda que algumas seções não fossem assinadas. A instrução construía modelos de leitor e leitora ao mesmo tempo em que acionava diferentes definições do que era "normal" ao aconselhar casos particulares, revelando que as fronteiras da "normalidade" não se limitavam ao campo médico.

\section{As modernas leituras da normalidade}

A medicina era um dos discursos que reforçavam papéis sociais "modernos" segundo as diferenças sexuais, com destaque para as colaborações do psiquiatra Wilhelm Steckel e do psicanalista Gastão Pereira da Silva. Segundo eles, a mulher "normal", "passiva por natureza", era aquela capaz de cuidar da família e dos filhos, em contraste com a mulher "nervosa", que não cumpria tais funções por ser "cheia de manias". O homem "normal", por sua vez, preservaria a função de pai e trabalhador, responsável pela robustez e sustento de sua descendência (Steckel, 6 set. 1945, p.50). A função primeira de ambos seria a preservação da espécie e o desenvolvimento da família/nação, desde que respeitassem sua respectiva "natureza" (Silva, 21 nov. 1940, p.56). Apoiadas na biologia, as representações médicas de "mulher e homem normais" eram normativas e universalistas, sendo quaisquer variações a esses modelos consideradas anormais e passíveis de intervenção (Facchinetti, 2014).

Já os conselheiros que assinavam as seções de correspondência tinham uma concepção mais fluída de normalidade, pois reconheciam que os/as consulentes estavam sempre presos/as a casos pessoais, mesmo quando procuravam generalizar (Dix, 17 abr. 1941, p.40). Em vez de discursar sobre o homem ou a mulher, consideravam as particularidades narradas nas cartas, contribuindo para ampliar a polifonia das representações de gênero ao desviar do modelo médico universal e normativo.

Ainda que a maioria das cartas fosse de mulheres jovens e solteiras que buscavam orientação sobre namoro, trabalho e leituras saudáveis, algumas narrativas eram acionadas como referências. É o caso da senhora Creuza Castelar, 52 anos, elogiada pela conselheira Maria Luiza (29 fev. 1941, p.50) em "Os homens são assim..." por sua maturidade "despida de complexos". Os homens também pediam conselhos sobre relacionamentos, revelando-se inseguros com a liberdade feminina, que também respingava sobre os papéis masculinos. Alguns não poupavam nem as conselheiras, acusadas de sugestionar as leitoras com "ideias emancipatórias" e "levá-las à loucura" (Floriano, 3 abr. 1941, p.50).

Longe de produzir consenso, as cartas revelam visões conflitantes a respeito da nova realidade social. Embora constituísse há muito uma realidade entre mulheres mais pobres, o trabalho era alvo de desconfiança: os homens enfatizavam que "a mulher nasceu para ser mãe", visão endossada por mulheres que lamentavam que o homem não encontrava na mulher moderna "a edificadora de um lar", apesar de ser celebrada por ter "muito que encher a sua vida: o trabalho, o estudo, o esporte, a literatura" (Filho, 24 abr. 1941, p.51; Anônima, 20 mar. 1941, p.30). O feminismo, embora "um sintoma de que pertencemos ao século XX", não significaria igualdade de direitos, pois "a 'verdade' é que 'nascemos' para sermos antes de tudo esposa e mãe" (Maria, 20 mar. 1941, p.31; destaque meu).

Em contrapartida, as vivências pessoais permitiam questionar essas premissas, como a leitora Ritinha (27 mar. 1941, p.50), 32 anos, que afirmava: "não sou aquilo que chamam 
a rigor de 'mulher honesta', mas sou senhora da minha vida, trabalho e sou mãe". Quando questionadas como "antinaturais" por conjugar as funções de "mãe, esposa e trabalhar em igualdade de condições com os homens", tais mulheres "modernas" respondiam que a maternidade em nada comprometia "nossa independência moral e material" (Luiza, 3 abr. 1941, p.50).

O trabalho fora do lar é um exemplo de como, embora os modelos tradicionais não tivessem desaparecido, naquele momento era possível confrontar a condição "natural" das mulheres e, por extensão, dos homens. As experiências individuais passavam a se afirmar como referências legítimas nas considerações do que era adequado e aceitável para si e para o outro, conferindo uma pluralidade de vozes e lugares de enunciação nas definições de ser e dos papéis sociais. Para os leigos, a normalidade se apresentava de forma plural, mais articulada a práticas reais e cotidianas dos sujeitos do que apoiada em ideais universais (Gráfico 1).

\section{Gráfico 1: Questões com as quais a normalidade aparece articulada}

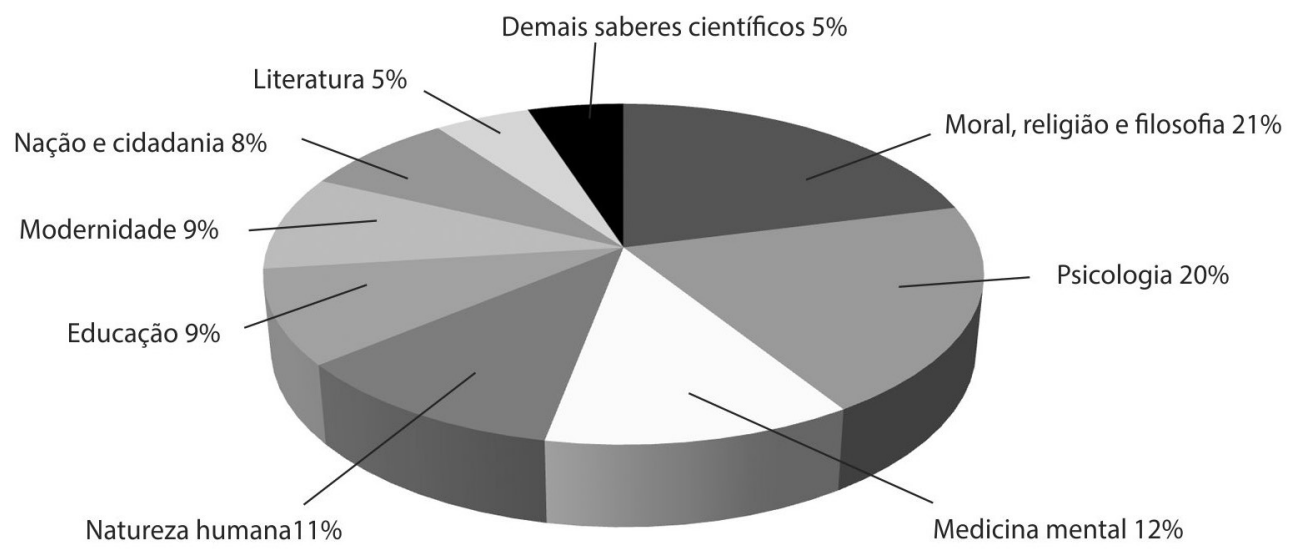

(Fonte: Carvalho, jul. 2016, p.32)

O discurso médico era apenas um dos muitos fios que compunham a rede de representações modernas de "mulher e homem normais". Ainda que a "medicina mental" (12\%) estivesse presente em cuidados profiláticos e higiênicos da saúde mental dos leitores, aparece em disputa e diálogo com "demais saberes científicos" (5\%), como a biologia e a fisiologia, na definição da normalidade. "Moral, religião e filosofia" (20\%) continuavam presentes em assuntos que tratavam do indivíduo, mas agora dividiam espaço com a "psicologia" (20\%) enquanto especialidade voltada para o autoconhecimento, com destaque para o inconsciente psicanalítico. A ideia de "natureza humana" (11\%) continuava ancorando a definição de "homem" e "mulher", embora a "modernidade" (9\%) tornasse tal natureza discutível, sobretudo quando anunciava os impactos da emancipação feminina sobre os papéis sociais de mulheres e homens. A "educação" (9\%) era compreendida como baluarte da saúde mental e moral do brasileiro, enquanto "nação e cidadania" (8\%) mobilizavam essa saúde como uma das garantias do progresso. Tratando-se de uma revista sensível à leitura, os modelos advindos da "literatura" (5\%) também eram incluídos na conformação das categorias de homem e mulher, dando aos modelos a aparência de personagens de romance. 


\section{Considerações finais}

A definição da "normalidade" passava ainda pela discussão do que era ser brasileiro, uma vez que a saúde mental da população era afirmada como uma garantia importante do desenvolvimento da nação, com especial destaque para a mulher e a infância (Kuhlmann Jr., Magalhães, 2010). Ao fomentar esse debate, Vamos Ler! se apresentava como cenário onde tais questões eram discutidas e articuladas a referenciais alternativos à medicina, permitindo leituras modernas de modelos até então "naturais" de homem e mulher que passavam a disputar o status de verdade com identidades mais tradicionais (Facchinetti, Carvalho, no prelo).

A análise de cartas junto a outras publicações de Vamos Ler! permitiu confirmar as hipóteses levantadas a respeito de uma apropriação seletiva da categoria "normalidade" da medicina mental por leigos. Embora o sexo e a biologia não tenham desaparecido como referências na construção dos papéis sociais, os modelos tradicionais já não tinham o mesmo peso de autoridade, visto que o trabalho feminino fora do lar e as relações amorosas e familiares, como experiências individuais, constantemente apareciam como arranjos que interferiam na definição do que era adequado e normal segundo essas pessoas.

As cartas ressaltaram ainda a importância da subjetividade para o estudo de representações de gênero. Ao incentivar seus leitores, Vamos Ler! compartilhava diferentes narrativas a respeito da nova realidade social, trazendo à tona os conflitos íntimos que atravessavam as leituras de mundo de homens e mulheres, assim como as negociações possíveis aos modos de ser e comportar-se modernos. Isso permitiu realçar as apropriações e os usos práticos que conselheiros e missivistas fizeram dos saberes que se encontravam disponíveis ao versar de forma diversificada sobre a mulher e o homem brasileiros normais.

\section{NOTAS}

${ }^{1}$ Os resultados aqui apresentados são de uma pesquisa de iniciação científica orientada pela prof. dra. Cristiana Facchinetti (COC/Fiocruz), que na época pesquisava sobre as representações de normalidade, anormalidade e patologia em revistas médicas especializadas (Arquivos Brasileiros de Higiene Mental e Arquivos Brasileiros de Neuriatria e Psiquiatra) e leigas (A Cigarra, Jornal das Moças e Vamos Ler!) durante a Era Vargas (1930-1945). Em diálogo, o subprojeto de iniciação científica concentrou-se nas representações de normalidade, a fim de identificar as apropriações leigas dessa categoria.

${ }^{2}$ Isso impactou o mercado literário nacional, com significativo crescimento de publicações e editoras, como José Olympio, Companhia Editora Nacional e Livraria Globo (Ferreira, Delgado, 2003).

\section{REFERÊNCIAS}

ANÔNIMA.

Os homens são assim... Vamos Ler!, n.242, p.30.

20 mar. 1941.

BASTOS, Maria Helena Camara; CUNHA, Maria Teresa Santos; MIGNOT, Ana Chrystina Venancio.

Destinos das letras: história, educação e escrita epistolar. Passo Fundo: UPF. 2002.
BRASIL.

Decreto-lei n. 2.703 de 8 de março de 1940.

Disponível em: http://legis.senado.gov.br/

legislacao/ListaPublicacoes.action?id=41183. Acesso em: 17 jul. 2017. 1940.

BUITONI, Dulcília Schroeder.

Mulher de papel: a representação da mulher pela imprensa feminina brasileira. São Paulo: Summus. 2009. 
CARVALHO, Carolina da Costa de.

A revista Vamos Ler! e seus leitores: uma análise das relações de gênero (1936-1948). Relatório final de pesquisa de iniciação científica (PIBIC/ CNPq). Rio de Janeiro: Casa de Oswaldo Cruz/ Fiocruz. jul. 2016.

CHARTIER, Roger.

A história cultural: entre práticas e representações. Rio de Janeiro: Difel/Bertrand Brasil. 2002.

\section{CHARTIER, Roger.}

Diferenças entre os sexos e dominação simbólica (nota crítica). Cadernos Pagu, v.4, p.37-47. 1995.

CUPELlO, Priscila Céspede.

A mulher (a)normal: representações do feminino em periódicos científicos e revistas leigas na cidade do Rio de Janeiro (1925-1933). Dissertação (Mestrado em História das Ciências e da Saúde) - Casa de Oswaldo Cruz/Fiocruz, Rio de Janeiro. 2013.

DIX, Irene.

Os homens são assim... Vamos Ler!, n.246, p.40. 17 abr. 1941.

FACCHINETTI, Cristiana.

Júlio Pires Porto-Carrero: a psicanálise como ferramenta para a "Idade de Ouro" no Brasil. In: Hochman, Gilberto; Lima, Nísia Trindade (Org.). Médicos intérpretes do Brasil. Rio de Janeiro: Hucitec. p.1-20. 2015.

FACCHINETTI, Cristiana.

Normal, anormal, patológico: representações de gênero no Estado Novo. Relatório final de pesquisa (APQ1-FAPERJ). Rio de Janeiro. 2014.

FACCHINETTI, Cristiana; CARVALHO, Carolina da Costa de.

Loucas ou modernas? Mulheres modernistas em revista (1920-1940). Revista do Arquivo Geral da Cidade do Rio de Janeiro. No prelo.

FERREIRA, Jorge; DELGADO, Lucília de Almeida Neves (Org.).

O Brasil republicano: o tempo do nacional estatismo do início da década de 1930 ao apogeu do Estado Novo. Rio de Janeiro: Civilização Brasileira. 2003.

FILHO, Plínio.

Os homens são assim... Vamos Ler!, n.247, p.51.

24 abr. 1941.

FLORIANO, Léo.

Os homens são assim... Vamos Ler!, n.244, p.50.

3 abr. 1941.

FONSECA, Cristina.

Saúde no governo Vargas, 1930-1945: dualidade institucional de um bem público. Rio de Janeiro: Fiocruz. 2007.
FREIRE, Maria Martha de Luna.

Mulheres, mães e médicos: discurso maternalista no Brasil. Rio de Janeiro: FGV. 2009.

KUHLMANN JR., Moysés; MAGALHÃES, Maria das Graças Sandi.

A infância nos almanaques: nacionalismo, saúde e educação (Brasil 1920-1940). Educação em revista, v.26, n.1, p. 327-349. 2010.

LUCA, Tania Regina de.

História dos, nos e por meio dos periódicos. In: Pinsky, Carla (Org.). Fontes históricas. São Paulo: Contexto. 2005.

LUIZA, Maria.

Os homens são assim... Vamos Ler!, n.244, p.50. 3 abr. 1941.

LUIZA, Maria.

Os homens são assim... Vamos Ler!, n.239, p.50. 29 fev. 1941.

MARIA, Yara.

Os homens são assim... Vamos Ler!, n.242, p.31. 20 mar. 1941.

MELLO, Antonio Vieira de.

"Vamos Ler! e a publicidade". Vamos Ler!, n.211, p.25. 15 ago. 1940.

MIRANDA, Hermínio de.

Dê sua opinião... por 20\$000. Vamos Ler!, n.244, p.44. 3 abr. 1941.

RITINHA.

Os homens são assim... Vamos Ler!, n.243, p.50. 27 mar. 1941.

SCHWARTZMAN, Simon; BOMENY, Helena

Maria Bousquet; COSTA, Vanda Maria Ribeiro. Tempos de Capanema. São Paulo: Paz e Terra. 2000.

SCOTT, Joan.

Prefácio a Gender and Politics of History.

Cadernos Pagu, v.3, p.11-27. 1994.

SILVA, Gastão Pereira da.

Psicologia da vida quotidiana. Vamos Ler!, n.225, p.56. 21 nov. 1940.

STECKEL, Wilhelm.

Educação aos pais. Vamos Ler!, n.475, p.50. 6 set. 1945.

VENANCIO, Ana Teresa.

Ciência psiquiátrica e política assistencial: a criação do Instituto de Psiquiatria da Universidade do Brasil. História, Ciências, SaúdeManguinhos, v.10, n.3, p.883-900. 2003. 